Z. klin. Chem. u. klin. Biochem.

7. Jg., S. $325-332$, Juli 1969

\title{
Porphyrin analysis in a case of a hyporegenerative anaemia ${ }^{1}$ )
}

\author{
By H. Mundschenk and J. Fischer \\ From the I. Medizinische Klinik and Poliklinik of the University of Mainz, BRD
}

(Eingegangen am 11. März 1969)

\section{Herrn Prof. Dr. J. Brugsch qum 60. Geburtstag gunidmet}

Porphyrins are fractionated by a $\mathrm{pH}$ gradient on TBP columns ${ }^{2}$ ) according to the number of carboxyl groups(n); isomers, with the exception of CP-I/III, can be separated on the same columns, using $1 \mathrm{~N}$ hydrochloric acid as elutriant.

For identification, the predominant fractions were decarboxylated to the corresponding coproporphyrin derivatives. Separation on activated silica gel plates in the 2.6-lutidine/water system before and after decarboxylation revealed the degree of decarboxylation and the isomeric type by comparison of the $R_{F}$ obtained with those of pure reference substances.

In order to characterize the different fractions, some additional parameters are used:

1. The centre of the dissociation interval $x_{D}$ of the porphyrins, the carboxyl groups of which are converted into the anionic form. These values can be obtained with small amounts of material (min. $1 \mu \mathrm{g}$ ) and a high accuracy $( \pm 0.05 \mathrm{pH}$ units) with the aid of the $\mathrm{pH}$ gradient on TBP columns.

2. The peak position of the soret band $\lambda_{\mathrm{p}}$ of the porphyrins, before and after decarboxylation. This determination can be carried out with amounts down to $0.2 \mu \mathrm{g}\left(\mathrm{c}_{\mathrm{HCl}}=1.00 \mathrm{~N}\right)$.

3. The retention time or volume of the single porphyrin fractions on TBP columns under standard conditions $\left(c_{\mathrm{HCl}}=1 \mathrm{~N} ; \mathrm{T}_{\mathrm{S}}=20^{\circ}\right)$.

By the methods described, it was possible to decompose the urinary porphyrin mixture of Patient $U$. into at least 27 fractions, most of which ranged in a total percentage of $0.1-2 \%$. This finding showed clearly that not only intermediate compounds of the haem synthesis are present in the mixture, but also fractions which differ from those with respect to their substituents (pseudoporphyrins).

From the iron kinetic studies with ${ }^{59} \mathrm{Fe}$ and the pattern of porphyrins in fig. 16 we may assume that the production of haem is also inhibited by a disordered reutilization of the iron.

Porphyrine werden auf TBP-Säulen im pH-Gradienten entsprechend der Anzahl der vorhandenen Carboxylgruppen fraktioniert; eine Auftrennung der Isomere, mit Ausnahme von CP-I/III, kann auf den gleichen Säulen bei Verwendung von $1 \mathrm{~N} \mathrm{HCl}$ als Elutionsmittel durchgeführt werden.

Zur Identifikation werden die extraktionschromatographisch erhaltenen Fraktionen decarboxyliert. Eine dünnschichtchromatographische Auftrennung, vor und nach der Decarboxylierung, im 2.6-Lutidin-Wasser-System gestattet, Isomerentyp und Decarboxylierungsgrad im Vergleich mit Substanzen bekannter Konstitution zu ermitteln.

Zur Charakterisierung der verschiedenen Fraktionen werden die folgenden Parameter herangezogen:

1. Dissoziationsstufe $\mathrm{x}_{\mathrm{D}}$, die den Ulbergang der Carboxylgruppen der Porphyrinmolekel in die anionische Form kennzeichnet. Diese Werte können auf TBP-Säulen mit Mengen von min. $1 \mu \mathrm{g}$ mit hoher Genauigkeit ( $\pm 0,05 \mathrm{pH}$-Einheiten) ermittelt werden.

2. Peaklage der Soretbande $\lambda_{\mathrm{p}}$ der Porphyrine, vor und nach der Decarboxylierung. Zu dieser Bestimmung in $\mathrm{c}_{\mathrm{HCl}}=1,00 \mathrm{~N}$ genügen Mengen von min. 0,2 $\mu \mathrm{g}$.

3. Retentionszeit bzw. -volumen $x_{p}$ der Porphyrinfraktionen bei der Trennung auf TBP-Säulen unter Standardbedingungen.

Mit den beschriebenen Verfahren konnte das aus dem Urin von Patient U. isolierte Porphyringemisch in 27 Fraktionen zerlegt werden. Dieser Befund beweist, daß nicht nur die bei der Hämsynthese auftretenden Zwischenglieder in der Probe vorliegen, sondern darüber hinaus Fraktionen, die sich offenbar durch die vorhandenen Substituenten von diesen unterscheiden (Pseudoporphyrine).

Aus den ferrokinetischen Untersuchungen mit ${ }^{5} \mathrm{Fe}$ und dem quantitativen Verteilungsmuster der Porphyrine (Fig. 16) wurde geschlossen, daß im vorliegenden Fall die Einschränkung der Erythropoese auch auf eine Störung der Eisenreutilisation zurückgeht, die offenbar den eigentlichen Engpaß in der Hämsynthese darstellt.

\section{Introduction}

The analysis of complex porphyrin mixtures, excreted in urine and faeces, may give us a fairly precise picture of the biosynthesis of haem, which occurs chiefly in the liver and the bone marrow. In order to obtain detailed information on the dynamic process of the conversion of uroporphyrin to protoporphyrin by successive decarboxylation, the haem precursors must be identified not only as regards the number of carboxyl groups in the side-chains of the tetrapyrrolic nucleus, but also as to their isomeric type.

In pathological cases the urinary porphyrins are often numerous and their structure sometimes unknown. Therefore the identification and quantitation of the

1) Presented in part at the XIIth Congress of the International Society of Hematology, New York, Sept. 1-6, 1968. single fractions by the methods commonly used may be impedèd to a greater or less extent. Thus the fractionation of two common porphyrin isomers, uroporphyrin I and III, by the generally applied dioxan method (1) which presupposes the esterification of the two compounds, is only applicable to samples, the composition of which does not exceed certain limits (2). Furthermore there is no method available, by which separation and identification of fractional decarboxylated porphyrins (hepta-, hexa- and pentacarboxyl porphyrins) and their isomers can be performed simultaneously. In these cases, it is advisable first to separate these haem precursors and then to decarboxylate the fractions obtained to the corresponding coproporphyrin derivatives. These can be analyzed ac-

2) $\mathrm{TBP}=$ tri-n-butylphosphate. 


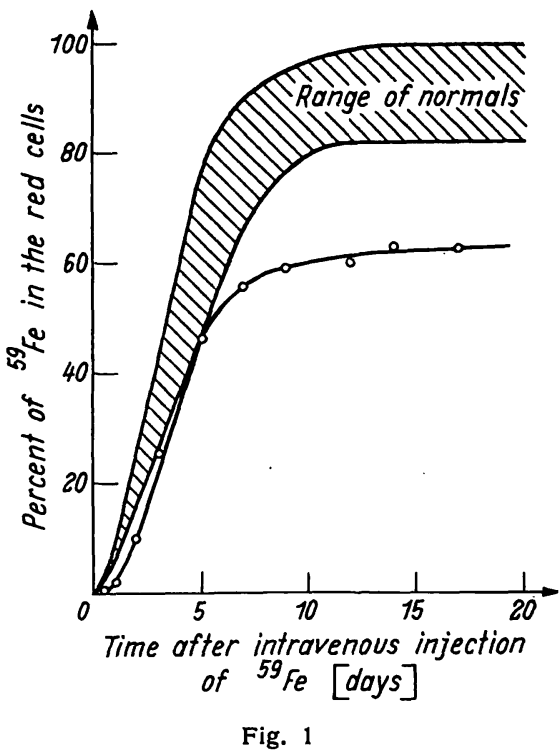

Iron uptake by the red cells as a function of time after intravenous injection of appr. $40 \mu \mathrm{C}{ }^{\circ} \mathrm{Fe}$

cording to their isomeric type by the usual chromatographic procedures $(3,4)$.

The case to be reported here is a hyporegenerative anaemia, aged 60. Iron kinetic studies with ${ }^{59} \mathrm{Fe}$ revealed a significant decreased iton utilization of $63 \%$ (Fig. 1).

The tracer was eliminated from the plasma with a slightly increased half life of $125 \mathrm{~min}$. The iron turnover was found to be normal $(0.79 \mathrm{mg} \mathrm{Fe} / 100 \mathrm{ml}$ blood). Surface measurements revealed a decreased incorporation of iron by sacrum and sternum in comparison to that found in normal cases. The apparent half life of the erythrocytes, determined with ${ }^{51} \mathrm{Cr}$, was found to be almost normal $\left(T_{1 / 2}=25 \mathrm{~d}\right)$. The hematocrit, measured over a period of several weeks, fluctuated between 26 and $34 \%$; the counts of the reticulocytes in the same time were found in the limits of $1.6-3.9 \%$. The porphyrin mixture, isolated from the urine, proved to be very complex. A separation by thin layer technique on activated silica gel plates in the 2.6-lutidine-water system revealed more than 9 distinct spots, the most predominant of which are found at low $R_{\boldsymbol{F}}$ values (Fig. 2, f 1, 2).

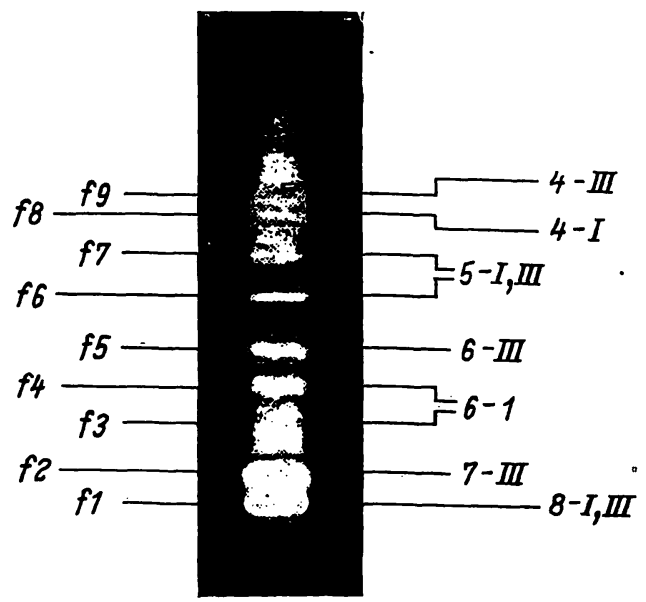

Fig. 2

Thin layer chromatogram of the urinary porphyrin mixture of Patient U., separated on activated silica gel plates in the 2.6-lutidine-water system
Further attempts to improve the separation by varying the composition of the developing solvent failed.

Because it was believed that more than 9 fractions occur in the sample studied, as found by TLC separations, the decomposition of the urinary porphyrin mixture was performed by means of two new extraction chromatographic procedures which have been described elsewhere in detail (6-9).

Whereas the separation in the partition system tri-nbutylphosphate/ $/ \mathrm{KH}_{2} \mathrm{PO}_{4}-\mathrm{Na}_{2} \mathrm{HPO}_{4}$ allows the fractionation of the porphyrins as regards the number of carboxyl groups in the side chains by $\mathrm{pH}$ gradient elution, differentiation of the isomers can be achieved in the tri-n-butylphosphate/1N hydrochloric acid system.

For purpose of identification, several characteristic parameters of the fractions obtained were determined:

1. Position of the peak in the elution chromatogram in the partition system:

a) tri-n-butylphosphate $/ 1 \mathrm{~N} \mathrm{HCl}: \mathrm{x}_{\mathrm{p}}$;

b) tri-n-butylphosphate $/ \mathrm{KH}_{2} \mathrm{PO}_{4}-\mathrm{Na}_{2} \mathrm{HPO}_{4}: \mathrm{x}_{\mathrm{D}}$.

2. Peak position of the soret band $\lambda_{p}$ of the porphyrins, before and after decarboxylation.

3. $R_{F}$ values in the 2.6-lutidine-water system with activated silica plates, before and after decarboxylation.

\section{Experimental}

In previous studies we found (10) that porphyrins can be extracted rapidly from urine by tri-n-butylphosphate taking advantage of the so-called filter bed technique. By this procedure, the porphyrins can be separated from most of the other urinary compounds in a state of relatively high chemical purity. Furthermore this procedure is advantageous because of its rapidity and selectivity.

The procedure is performed as follows: A fine-grained powder of silica gel or hostaflon C 2 (a polytrifluorochloroethylene), particle size $50-100 \mu \mathrm{m}$, is impregnated with the extraction solvent (tri-n-butylphosphate) at a ratio of $2: 1(\mathrm{w} / \mathrm{w})$. The impregnated material is suspended $(3-5 \mathrm{~g} / 100 \mathrm{~m} / \mathrm{urine})$ in the weakly acidified urine $(\mathrm{pH} 1-3)$ and the suspension shaken vigorousily for a few seconds. After that, the urine is sucked through a glass filter at high flow rate. The filtrate is passed once more over the same filter bed to ensure completeness of the extraction process. After washing with some $\mathrm{ml} 0.1 \mathrm{~N} \mathrm{HCl}$, the porphyrins extracted are eluted from the filter bed with $3 \times 3 \mathrm{~m} / 5 \mathrm{~N} \mathrm{HCl}$.

The behavior of uroporphyrin and coproporphyrin in the partition system tri-n-butylphosphate/hydrochloric acid on the filter bed can be represented by the distribution coefficients $K_{D B}$ which were determined for both porphyrins over a wide range of acid concentration (Fig. 3).

In Figure 4, the distribution coefficient $K_{D}$ for uroporphyrin and coproporphyrin in the liquid/liquid system tri-n-butylphosphate/ $\mathrm{KH}_{2} \mathrm{PO}_{4}-\mathrm{Na}_{2} \mathrm{HPO}_{4}$ is plotted as a function of $\mathrm{pH}$.

With regard to the significant differences of the behavior of both haem precursors in the two extraction systems, the fractionation of the porphyrins on chromatographic columns with a sufficient number of theoretical plates seemed to be promising. The set-up used for both procedures is outlined in Figure 5.

The main column has a length of 80 or $120 \mathrm{~cm}$ and an inner diameter of $5 \mathrm{~mm}$. It was packed with the impregnated hostaflon 


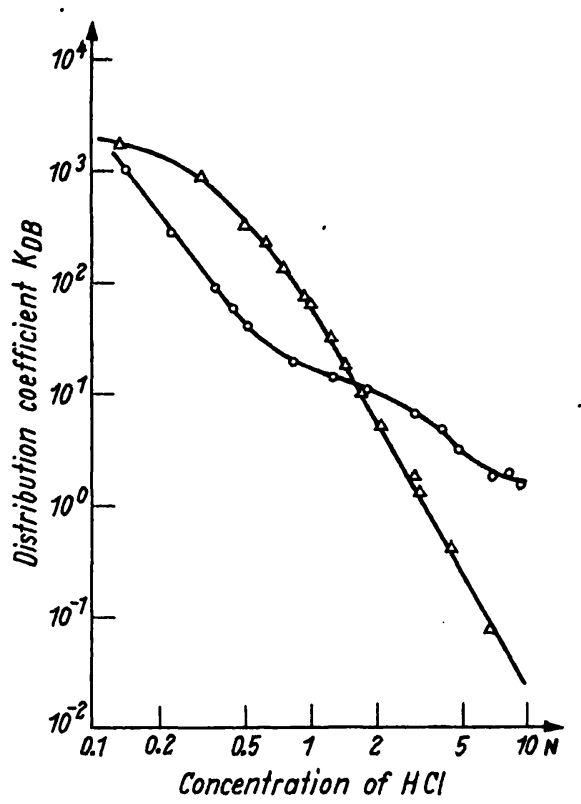

Fig. 3

Distribution coefficients $\mathrm{KDB}$ of uroporphyrin $(\Delta-\Delta)$ and coproporphyrin $(\circ)$ for the TBP filter bed system, plotted as a function of the acid concentration $\mathrm{CBCl}$

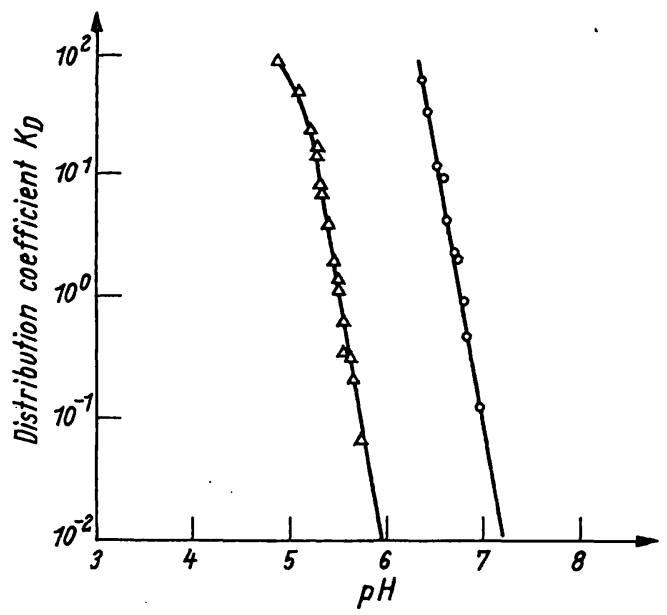

Fig. 4

Distribution coefficients $K_{D}$ of uroporphyrin $(\Delta-\Delta)$ and coproporphyrin $(\circ-0)$ for the liquid/liquid system TBP/M/15 Na $\mathrm{NPO}_{3}$ $\mathrm{M} / 15 \mathrm{KH}_{2} \mathrm{PO}_{4}$, plotted as a function of the $\mathrm{pH}$

powder, the same material as used in the filter bed procedure. The wash column (inner diameter: $15 \mathrm{~mm}$ ), also filled with impregnated hostaflon powder, was installed to saturate the elutriant with TBP. The porphyrins were absorbed in the top layer of the column from a weak acid solution $(\mathrm{pH} 1-3)$ at low flow rate. The separation was performed at a column temperature of $T_{s}=20^{\circ}$, using $1.00 \mathrm{~N}$ $\mathrm{HCl}$ or $\mathrm{M} / 15 \mathrm{KH}_{2} \mathrm{PO}_{4}-\mathrm{M} / 15 \mathrm{Na}_{2} \mathrm{HPO}_{4}$ as elutriant. The eluate, containing the separated fractions, is passed through a flow cuvette ( $1 \mathrm{~cm}$ MT $4 \mathrm{D}$; manufacturer: C. Zeiss, Oberkochen, BRD), in which the transmission of the solution is measured and recorded continuously by means of a spectrophotometric device (Zeiss spectrophotometer PMQ II with monochromator M 4 Q III). In this manner, the separation and quantitation of the single fractions can be performed simultaneously by determining the area of the recorded elution peaks. For this purpose, the calibration of the set-up with pure reference substances under the conditions used is necessary. In order to achieve satisfactory separations of the complex porphyrin mixtures, the operation conditions must be adjusted very accurately. This can be realized in a most simple way by varying the length of the column, whereas the other experimental parameters $\left(\mathrm{T}_{\mathrm{s}}, \mathrm{C}_{\mathrm{H}} \mathrm{Cl}\right)$ should be held constant.

The optimum experimental conditions (acid concentration: $c_{\text {BCl }}$; temperature of the column: $\mathrm{T}_{\mathrm{s}}$; slope of the $\mathrm{pH}$ gradient:

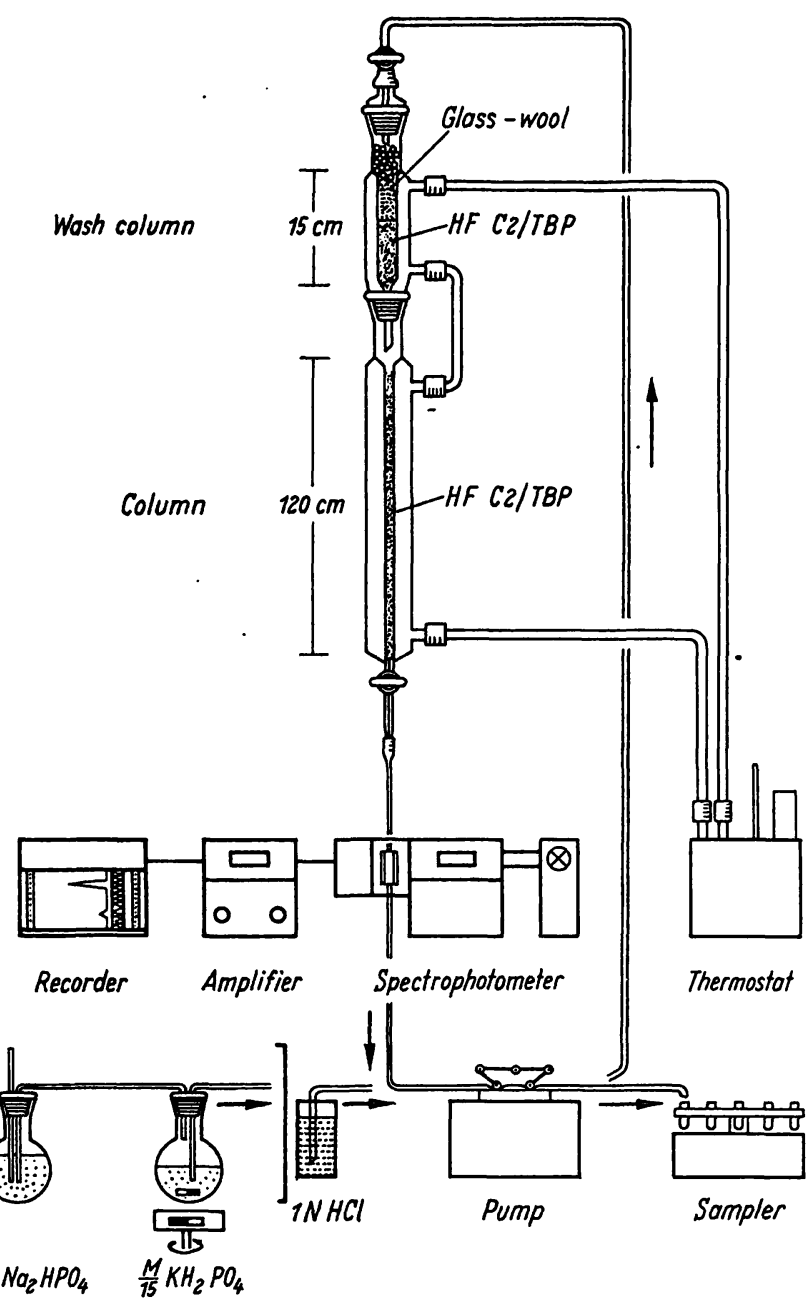

Fig. 5

The set-up used for the extraction chromatographic separations of complex porphyrin mixtures with a) $1 \mathrm{~N}$ hydrochloric acid and b) $\mathrm{M} / 15 \mathrm{Na}_{2} \mathrm{HPO},-\mathrm{M} / 15 \mathrm{KH}_{2} \mathrm{PO}_{4}$ ( $\mathrm{pH}$ gradient elution) as elutriants

$\mathrm{dpH} / \mathrm{dt}$ ) for both partition systems were determined in previous studies $(6-9)$.

To maintain constant flow conditions, the aqueous phase is passed through the column by means of a mechanical proportioning pump. The eluted fractions from the column are collected in a sampler. The successive steps of the isolation of the porphyrins from the urine; separation on the column and quantitation from the area of the elution peaks are compiled in Figure 6.

\section{Results}

\section{Separation of the porpbyrins in the partition system} $T B P / 1 \mathrm{~N} \mathrm{HCl}$

The analysis of porphyrin mixtures by means of the methods described is advantageous because separation and quantitation of the single fractions can be performed simultaneously. In previous studies (9) we found that, under the conditions used, no noticeable losses or degradation of the haem precursors on the column occur. Furthermore, when isolated from the urine on the TBP filter bed, the free prophyrins can be processed immediately; conversion into other chemical derivatives, e. g., esters, is not necessary. The single fractions leaving the column, dissolved in $1 \mathrm{~N} \mathrm{HCl}$ and collected in the sampler can be further analyzed directly (e. g., determination of the peak position of the soret band, etc.). 


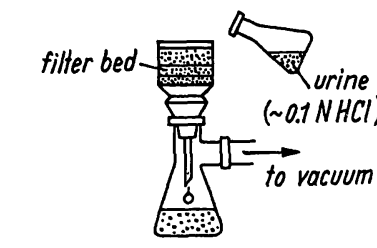

(7) Extraction of the porphyrins by the TBP filter bed from urine

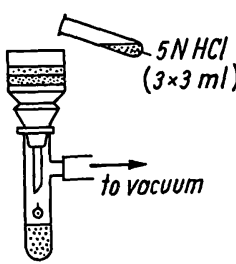

(2) Elution of the porphyrins from the filler bed with $5 \mathrm{~N} \mathrm{HCl}$

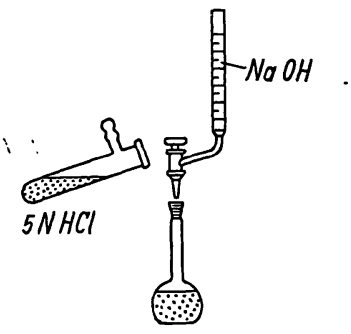

(3) Neutrolization of the acid solution of the porphyrins with $\mathrm{NaOH}$
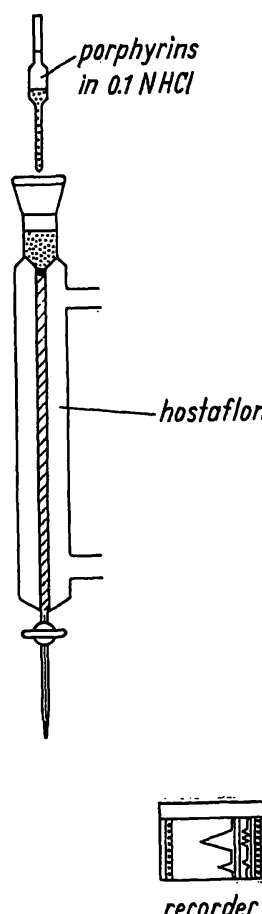

recorder
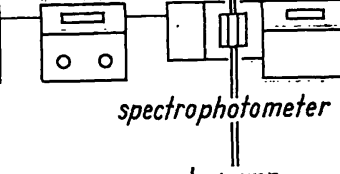

to pump

(5) Separation and simultaneous determination of the porphyrins

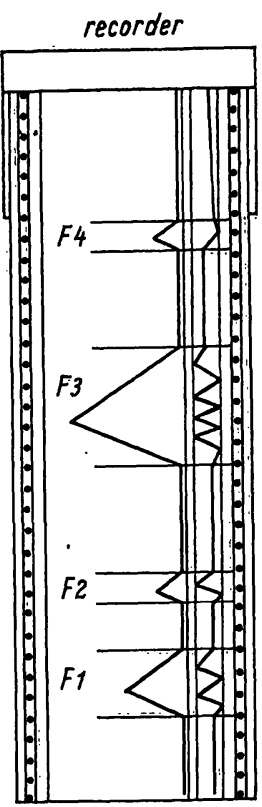

(6) Evaluation of the amount of the porphyrins from the peak areas

Fig. 6

Compilation of the successive steps applied to isolate porphyrins from urine, separate them on the TBP column and quantitate them from the area of the elution peaks

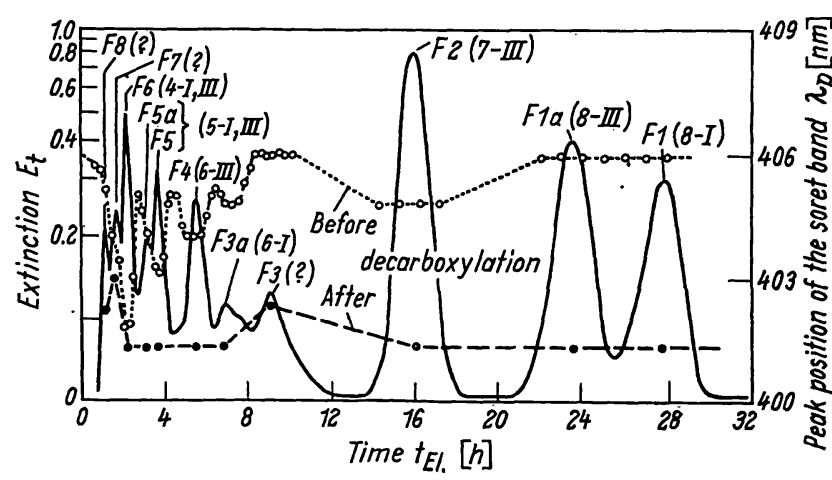

Fig. 7

Separation of the urinary porphyrin mixture of Patient $U$. by extraction chromatography in the partition system TBP/1 $\mathrm{NCl}$ (length of the column: $\mathrm{L}_{\mathrm{s}}=120 \mathrm{~cm}$; temperature of the column: $\mathrm{T}_{\mathrm{s}}=20^{\circ}$; acid concentration of the elutriant: $\mathrm{CHCl}_{\mathrm{H}}=1.00 \mathrm{~N}$; flow rate: $\mathrm{D}=$ fractions was determined before and after decarboxylation to the corresponding derivatives

A typical elution chromatogram, obtained from the urinary porphyrin mixture of our Patient $U$. is plotted in Figure 7.

For purpose of identification of the separated porphyrins, the peak position of the soret band of the predominant fractions was determined before and after conversion into the corresponding coproporphyrin isomers by decarboxylation. From measurements with pure reference substances, uroporphyrin-I/III and coproporphyrin-I/III, it is assumed that porphyrin isomers

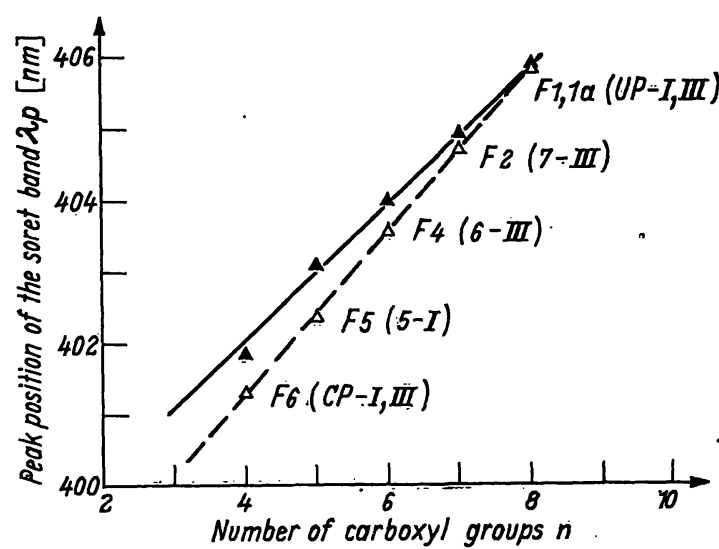

Fig. 8

The peak position of the soret band $\lambda p$ plotted as a function of the number of carboxyl groups of the porphyrin molecule (n). The observed values are corrected with respect to contaminating components, which were present in the fractions collected (Fig. 15). - - $\lambda_{p}=$ $f(n)$ observed, $\Delta--\Delta \lambda_{p}=f(n)$ corrected

exhibit identical $\lambda_{\mathfrak{p}}$ values. Therefore it can easily be determined whether two adjacent elution peaks are isomers or not. The strong correlation between the number of carboxyl groups (i) of the porphyrin molecule and the position of the soret band $\lambda_{p}$ is plotted in Figure 8.

The $\lambda_{p}$-value, the determination of which only requires minute amounts of the haem precursor (min. $0.2 \mu \mathrm{g}$ ), therefore indicates the degree of decarboxylation of the single porphyrin. Because the peak po- 


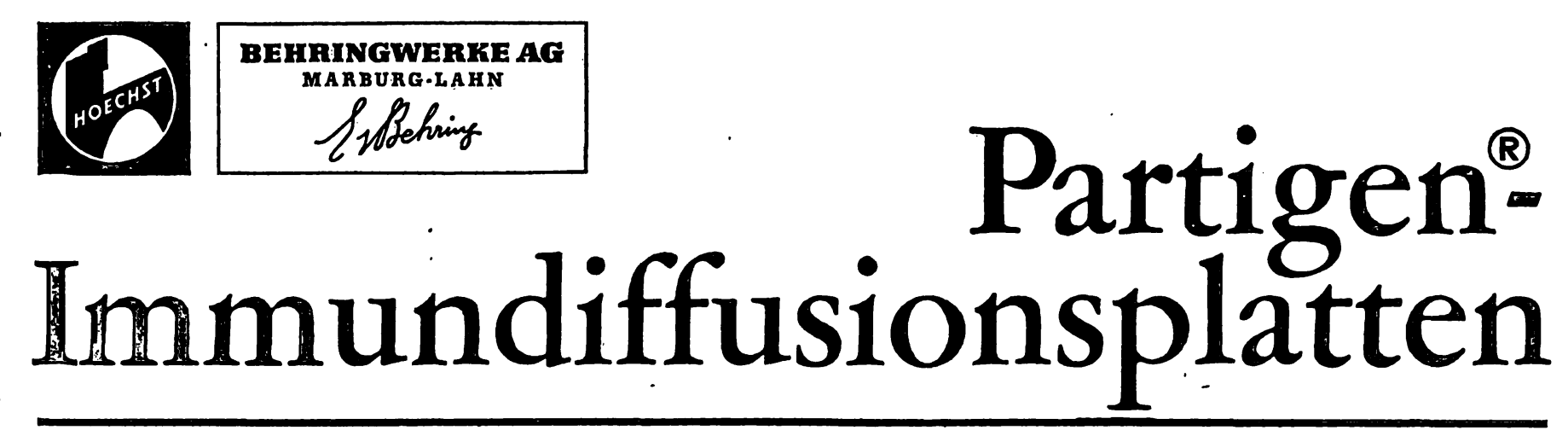

Antiserum-haltige Agargelplatten Behringwerke für quantitative Plasmaprotein-Bestimmungen
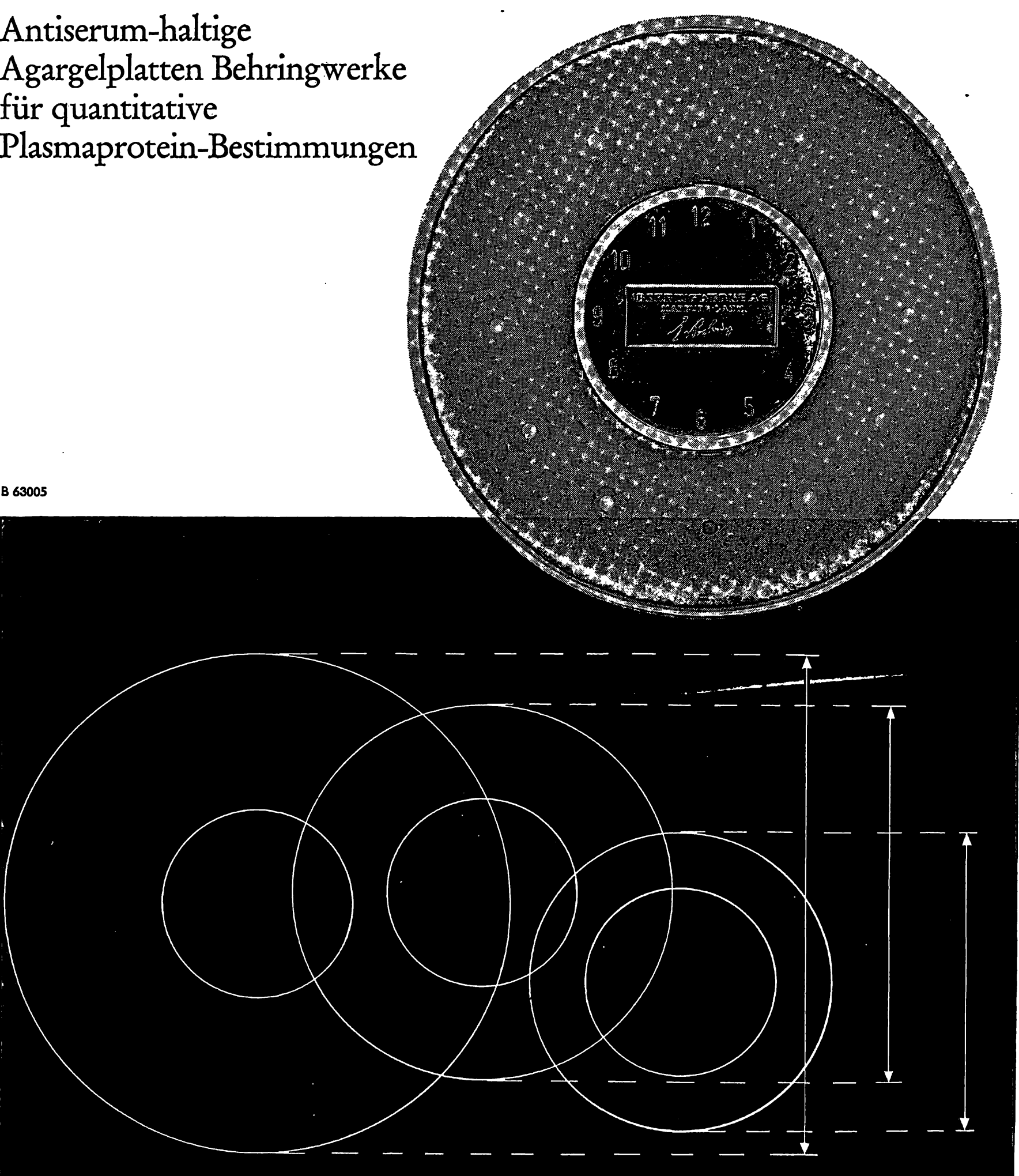


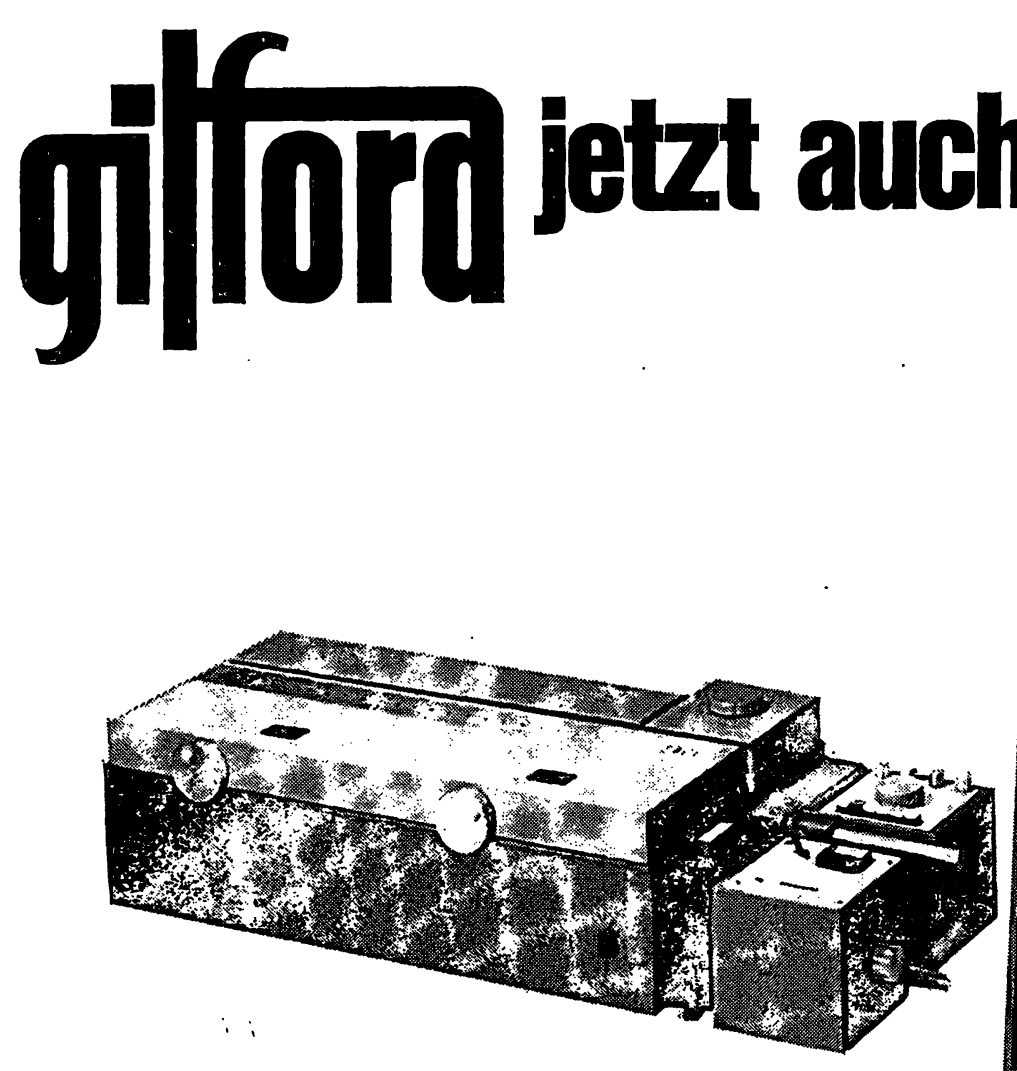

\section{GILFORD-Spektralphotometer 2400}

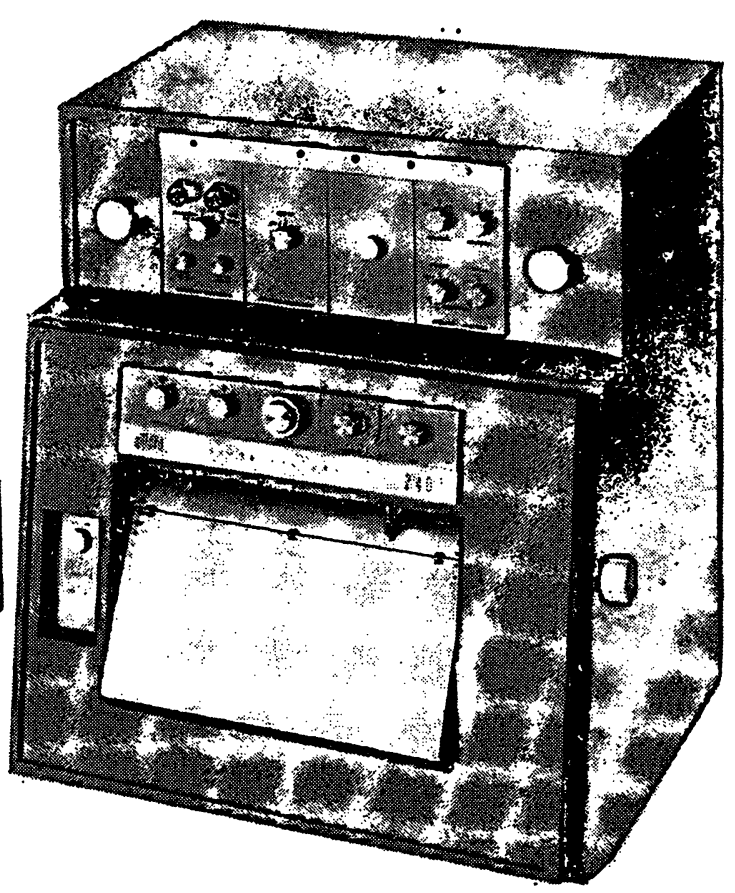

Ein präzises und vielseitiges Gerät für Forschungsaufgaben. Spektralbereich 185-999 nm. - Mit Registrierzusatz, Küvettenautomatik, Küvettentemperierung und vielen weiteren Vorteilen.

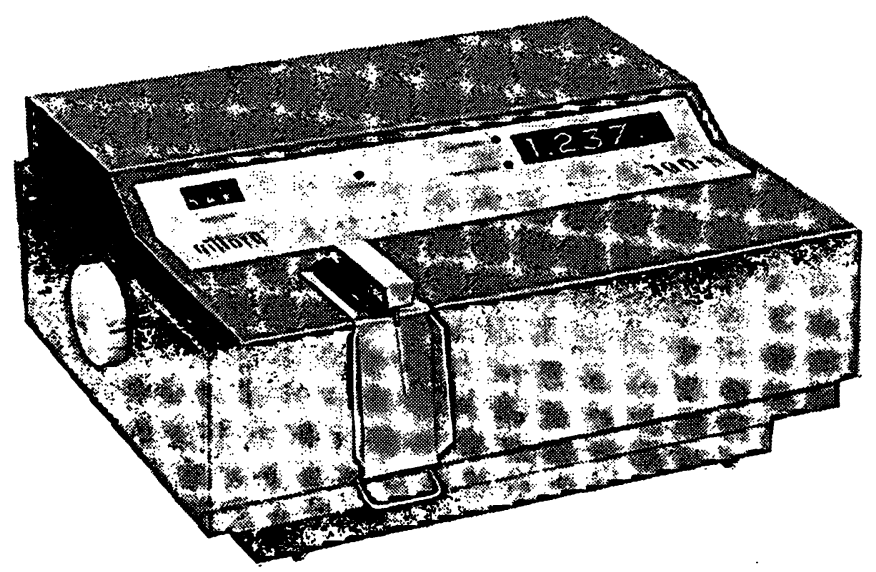

GILFORD-Mini-Spektralphotometer 300-N

Ein präzises Kompaktgerät für Routineaufgaben. Spektralbereich 340-700 nm. - Mehr als 200Bestimmungen/Stunde durch neuartige Durchflußküvette. Digitale Resultatanzeige in Extinktion oder Konzentration. - Auf Wunsch mit Datendrucker.

Wir liefern weiterhin:

Physiologische Instrumente zur Bestimmung des Herzminutenvolumens nach StewartHamilton. - Auswerter für Elektroferogramme. - Mikro-Durchflußküvetten. - Datenkonverter und Datendrucker.

GILFORD EUROPE S.A.

74, Rue M.S. Defresne

F-94 Vitry-sur-Seine

Telefon 7264370
6 Frankfurt NO 14

Brüder-Grimm-Straße 28

Telefon 434727 


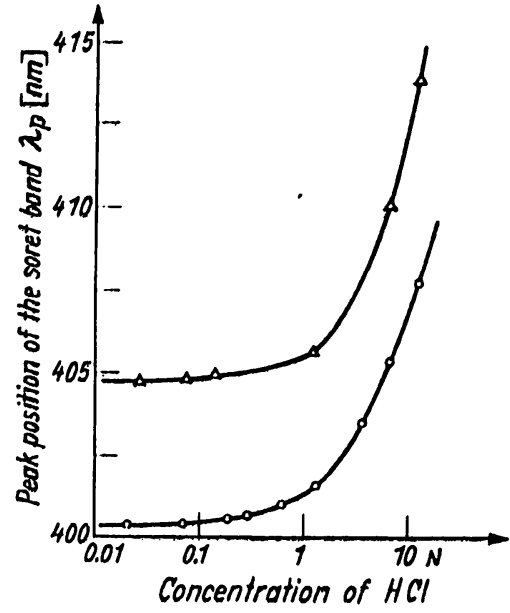

PIg. 9

The ponk position of the soret band $\lambda_{p}$ of uroporphyrin $(\Delta-\Delta)$ anc coproporphyrln (o-u) plotted as a function of acli concentration ctic

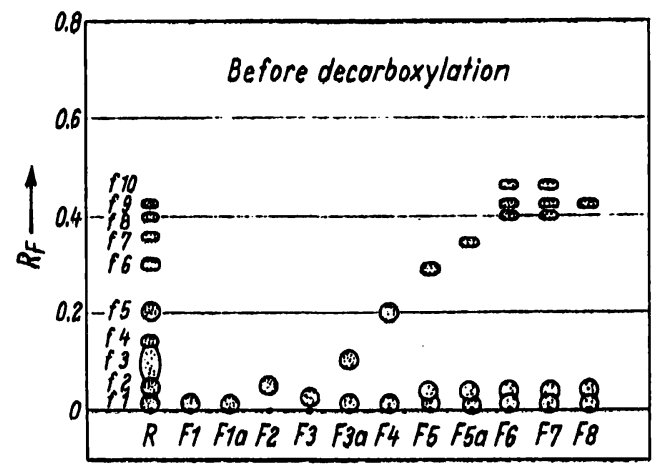

Fig, 10

Separation of the fractlons $F 1-8$, obtalned by extraction cliromatography on a TBP columu (F/g, 7), on actlvated silica gel plates in the 2.6-lutidiue-water systom, before decarboxylatlon. Thie unprocessed. urinary porphyrin mixture of Patient $U$. Is used as reference (R)

sition of the soret band is strongly dependent on the acid concentration, the $\mathrm{c}_{\mathrm{rucl}}$ value of the solution of the porphyrin must be adjusted very accuratcly (Fig. 9).

The fractions collected are separated by thin layer chromatography on activated silica gel plates in the 2.6-lutidine-water system (Fig. 10). As in paper chromatography (5), the degree of decarboxylation can be derived from the $R_{F}$ obtained in these separations.

Although great care was taken when collecting the single fractions from the column, several samples (F 5, 5a, 6, 7 and 8) split into more than two isolated spots on the platc. An explanation of this observation will be given later.

$\Lambda \mathrm{ftcr}$ decarboxylation of the main fractions, using the method described by EDMONDSON and Schwak'Tz (11), the resulting reaction products are separated in the same TLC system under identical conditions (Fig. 11). Hence it follows, that all fractions must be composed of at least two components. The occurrence of $f 10$ in the CP-II position (15) seemed to indicate at first glance, that, besides" the two isomers I and III of the intermedinte compounds of the haem reaction chain, a third isomer of type II was present in the sample. As will be shown later, some doubts arose as to whether this fraction 10 was really an isomer of type II, for

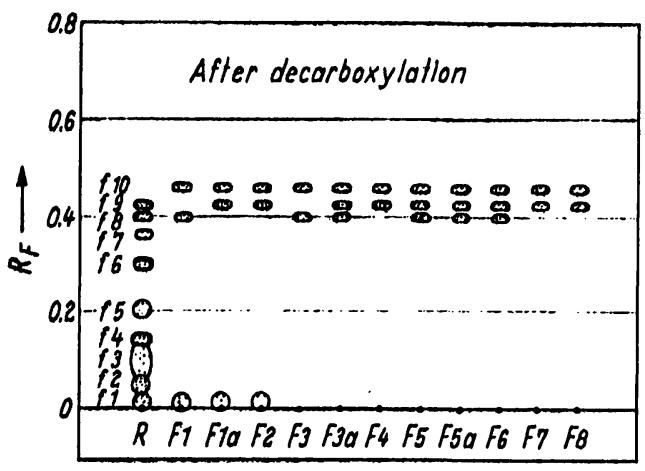

Figs 11

Separation of the Practions $F 1-8$, obtained by extraction chromatography on a'TBP colunin (Flg. 7), on activated sillca gel plates in the 2.0-lutidine-water system, after decarboxylation to the correspondling coproporphyrlin derlvatlves. The unprocessed urluary porphyrln mixture of Patlent U. Is used as reference (R) porplyr
.

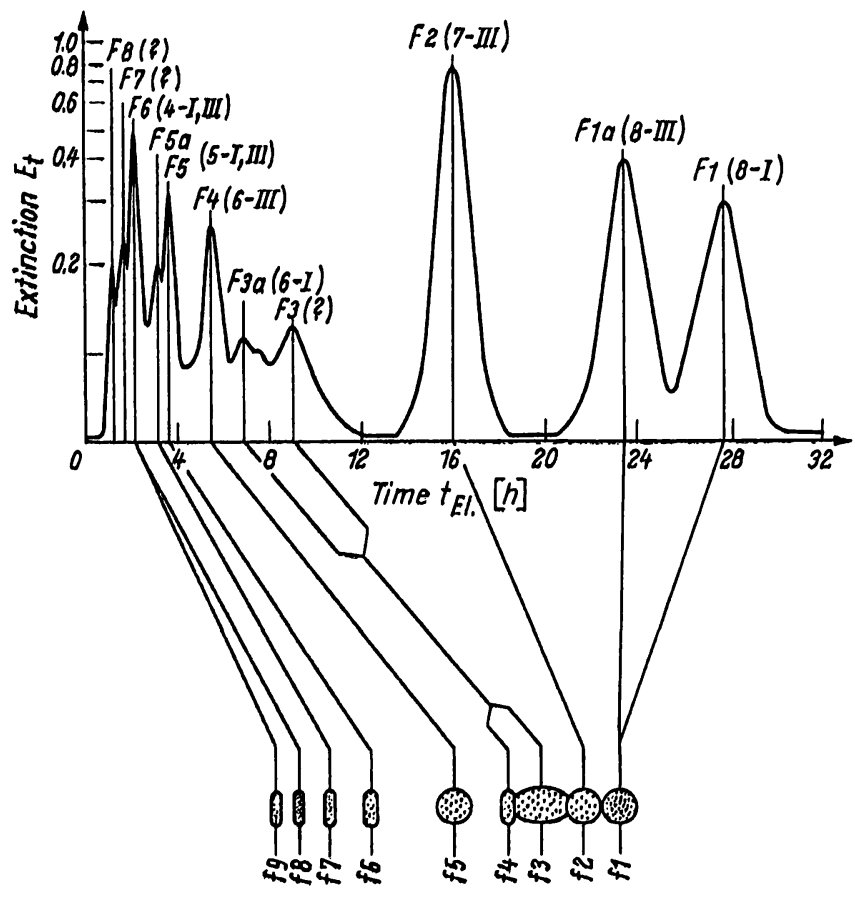

Fig. 12

Separation of the urinary porphyrin mixture of Patient $U$. on a) a TBP colunm 1 ising I $\mathrm{N} \mathrm{HCl}$ as elutriant (above) and

b) activated silica gel plates in the 2.6-lutidine-water system (below)

its position of the soret band did not agrec with that value expected for coproporphyrin isomers $\left(\lambda_{\mathrm{p}}=\right.$ $401.3 \mathrm{~nm} ; \mathrm{c}_{11 \mathrm{cl}}=1.00 \mathrm{~N}$ ).

A comparison of the thin layer and the clution chromatogram revealed the correlation between the spots of the former and the peaks of the latter (Fig. 12). From the 9 spots (TLC) and the 11 elution peaks $\left(E C / l_{\mathrm{N} \mathrm{HCl}}\right)$ it can be concluded that the porphyrin mixture of Paticnt $\mathrm{U}$. is apparently composed of at least 12 compounds.

Separation of the porplyyrins in the perrtition system TBP/M/15 $\mathrm{KH}_{2} \mathrm{PO}_{4}-\mathrm{M} / 15 \quad \mathrm{Na}_{2} \mathrm{HPO}_{4}$ by $p H$ gradient elution

From the plot of the distribution cocfficients $K_{1}$, of the two haem precursors, uroporphyrin and coproporphyrin, as a function of the pH (Fig. 4), it could be expected that porphyrins should be ensily separable by $\mathrm{pH}$ gradient elution. 
In a previous study (8) it was demonstrated that the transformation of the extractable form of the porphyrin molecule into the non-extractable one could be traced back to the dissociation of the carboxyl groups of the side-chains of the tetrapyrrolic nucleus. This was confirmed by spectrophotometric measurements which clearly indicated that the dislocation of the soret band takes place within the transformation interval at a discrete $\mathrm{pH}$.

The elution chromatogram obtained from the urinary porphyrin mixture of Patient $\mathrm{U}$. in a nonlinear $\mathrm{pH}$ gradient with the set-up shown in Figure 5 is presented in Figure 13. The variation of the $\mathrm{pH}$ as a function of time is plotted in the same diagram.

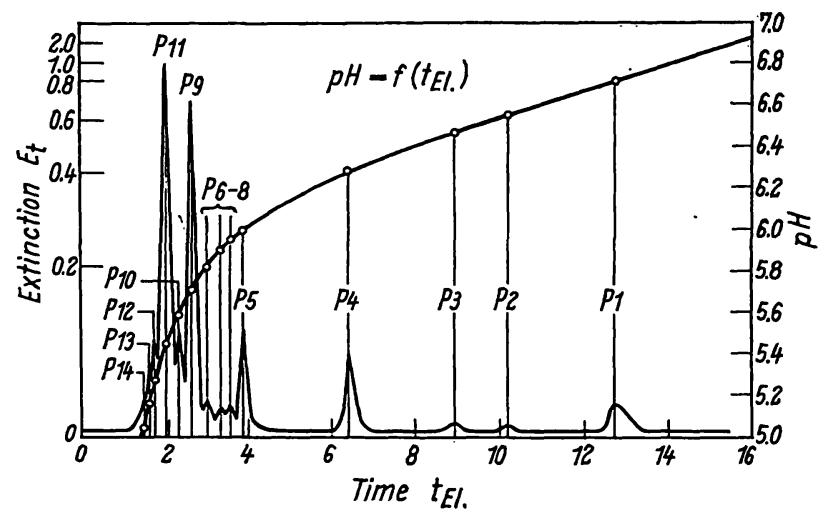

Fig 13

Separation of the urinary porphyrin mixture of Patient U. on a TBP column by $\mathrm{pH}$ gradient elution (length of the column: $\mathrm{L}_{\mathrm{s}}=120 \mathrm{~cm}$; temperature of the column: $T_{S}=20^{\circ}$; flow rate: $D=20 \mathrm{ml} / \mathrm{h}$; aqueous phase: $M / 15 \mathrm{Na}_{2} \mathrm{HPO}_{4}-M / 15 \mathrm{KH}_{2} \mathrm{PO}_{4}$ ). The variation of
$\mathrm{pH}$ of the aqueous phase is plotted as a function of time

Hence it follows that a strong correlation exists between the number of carboxyl groups of the porphyrin molecule (n) and the $\mathrm{pH}$. The position of the elution peaks $x_{D}$ agrees very well with the centre of the transformation interval (Fig. 4) and the dislocation of the soret band ((8) Fig. 6$)$ in the case of uroporphyrin and coproporphyrin. As the $\mathrm{x}_{\mathrm{D}}$ values could be reproduced with small deviations $( \pm 0.05 \mathrm{pH}$ units), this parameter seems to be excellently suited for the identification of the porphyrins with respect to the degree of decar-

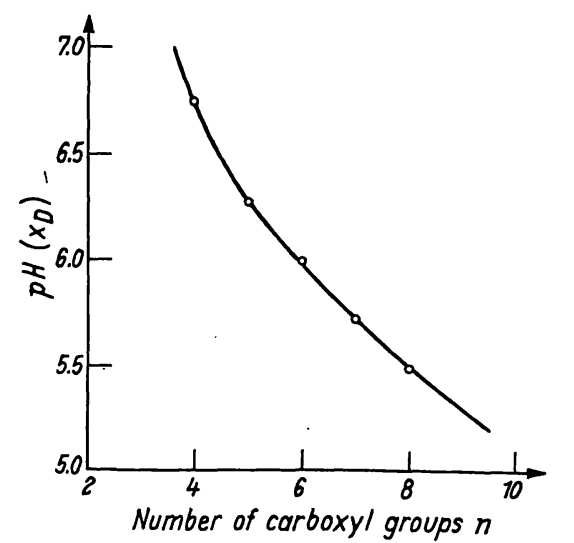

Fig. 14

The centre of the dissociation interval $x_{\mathrm{D}}$, which corresponds to the position of the elution peaks in the $\mathrm{pH}$ gradient elution (Fig. 13), plotted as a function of the number of carboxyl groups (n) of the
porphyrin molecule boxylation. The correlation between the number of carboxyl (n) and the $x_{D}$ values is plotted in Figure 14. The determination can be performed with amounts of porphyrins down to $\dot{1} \mu \mathrm{g}$. Although the slope of the $\mathrm{pH}$ gradient was reduced to values as low as 0.5 (uroporphyrin-I, III) and 0.1 (coproporphyrin-I, III) $\mathrm{pH}$ units/h, resp. no isomer fractionation could be observed under the conditions used.

Furthermore, the elution chromatogram contained several fractions ( $P$ 2, 3, 6, 7, 8, 12, 13, 14), whose presence was unexpected. In contrast to the predominant fractions, their total percentage was very small.

Thin layer separations (Fig. 10,11) revealed that the fractions, separated in the partition system tri- $n$ butylphosphate $/ 1 \mathrm{~N} \mathrm{HCl}$, consist of several components, some of them occurring at low $R_{\mathrm{F}}$. It therefore was assumed that the urinary porphyrin mixture of Patient U. contains more fractions than detected in the thin layer (9) and extraction chromatographic (11) sepa-
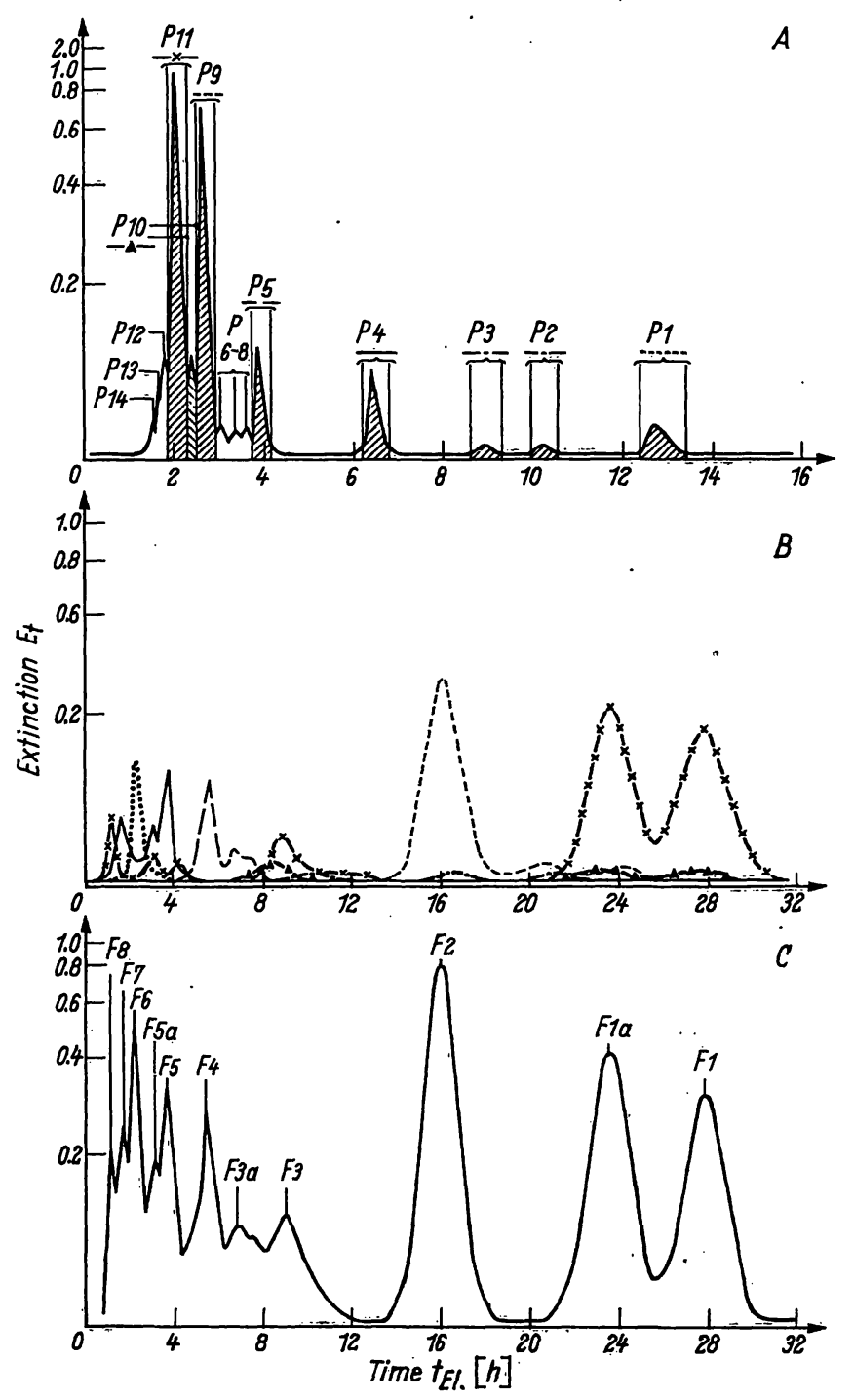

Fig. 15

Separation of the fractions $P$, obtained from the urinary porphyrin mixture of Patient $U$. by pH gradient elution (A), on a TBP column using $1 \mathrm{~N}$ hydrochloric acid as the eluant (B). For identification purposes, the elution chromatogram of the unprocessed porphyrin mixture, separated under the same experimental condition (Fig. 7 ) $_{\text {idded }}$ is 
rations alone. By combining the three procedures, it was expected that more detailed information about the composition of the porphyin sample would be obtained.

For this purpose, the porphyrin mixture was first separated with respect to the number of carboxyl groups by $\mathrm{pH}$ gradient elution. Afterwards the fractions within the cross-hatched peak areas (Fig. 15) were processed successively in the partition system tri-nbutylphosphate $/ 1 \mathrm{~N} \mathrm{HCl}$ under standard conditions (length of the column: $L_{s}=120 \mathrm{~cm}$; temperature of the column: $T_{s}=20^{\circ}$; acid concentration: $c_{\mathrm{HCl}}=1.00 \mathrm{~N}$ ). The elution chromatograms, obtained in the single runs, are compiled in Figure 15 (B). A comparison with the elution curves obtained with the original urinary porphyrin mixture in the $\mathrm{TBP} / 1 \mathrm{~N} \mathrm{HCl}$ (C) and the TBP $/ \mathrm{KH}_{2} \mathrm{PO}_{4}-\mathrm{Na}_{2} \mathrm{HPO}_{4}$ (A) system directly revealed the relationship between the different elution peaks.

By means of these procedures, the porphyrin mixture was resolved into at least 27 components, the majority of which occurred in a total percentage of $0.1-2 \%$. Hence it follows that, not only porphyrins belonging to the reaction chain of the haem synthesis are present in the porphyrin mixture, but also compounds which differ from the normal porphyrins by their substituents.

\section{Discussion}

The occurrence of at least 27 fractions in the urinary porphyrin mixture of Patient U. clearly showed that, besides the intermediate components of the isomeric types I and III (and probably II and/or IV) additional compounds must be present in the sample investigated. This can be demonstrated especially in the case of the uroporphyrin fraction $\mathrm{P} 11$.

From previous studies with UP-I/III and CP-I/III (8) it must be assumed that porphyrins are fractionated solely on the basis of their degree of decarboxylation by $\mathrm{pH}$ gradient elution on TBP. columns. Therefore all fractions with 8 carboxyl groups and the isomers of this haem precursor should be concentrated in P 11 (Fig. 13, 15). By decomposing $\mathrm{P} 11$ in the partition system TBP $/ 1 \mathrm{~N} \mathrm{HCl}$, at least 6 distinct fractions were obtained (Fig. 15). Although these compounds exhibit identical $x_{p}$ values, their $x_{p}$ values differed from each other'significantly; the position of the soret band $\lambda_{p}$ fluctuated between $405.2-405.9 \mathrm{~nm}$ (Tab. . 1). These values agreed fairly well with those obtained for the uroporphyrin.isomers I and III $\left(\lambda_{\mathrm{p}}=(405.7 \pm 0.1) \mathrm{nm}\right.$; $\mathrm{c}_{\mathrm{HCl}}=1.00 \mathrm{~N}$ ).

Hence it follows that fraction P 11 contained at least two derivatives which cannot be simple uroporphyrin isomers. From their behavior on the column in the partition system $\mathrm{TBP} / 1 \mathrm{~N} \mathrm{HCl}$ it was assumed that these were octacarboxyl prophyrins with additional hydrophilic substituents (e. g., $-\mathrm{OH}$ ) in the sidechains of the tetrapyrrolic nucleus. They were believed to be identical with compounds isolated by other authors (12) and called "pseudoporphyrin".
Tab. 1

Compilation of characteristic data $\left(\lambda_{\mathrm{p}}\right.$ : peak position of the soret band; $t_{F 1 .}$ : retention time obtained in the TBP/1N HCl system; $x_{D}$ : centre of the dissociation intervall; $R_{F}: R_{F}$ values observed in the
2.6 -lutidine-water system) of fractions obtained in the different 2.6-lutidine-water system) of fractions obtained in the different separating systems (EC/HCl: extraction chromatographic separation
in the partition system tri-n-butylphosphate/1 hydrochlorid acid (F);

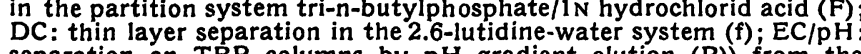

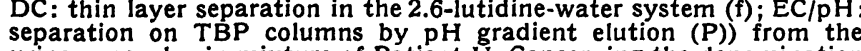
separation on TBP columns by $\mathrm{pH}$ gradient elution (P) from the
urinary porphyrin mixture of Patient U. Concerning the denomination urinary porphyrin mixture of Patient U. Concerning the de
of the different fractions $P$, see ref. $(8$, Fig. 12)

\begin{tabular}{|c|c|c|c|c|c|c|c|}
\hline $\mathrm{EC} / \mathrm{pH}$ & $x_{D}$ & $\mathrm{EC} / \mathrm{HCl}$ & $\begin{array}{c}t_{\text {El }} \\
\text { (h) }\end{array}$ & $\begin{array}{c}\lambda_{\mathrm{p}} \\
(\mathrm{nm})\end{array}$ & $\mathrm{DC}$ & $R_{\mathfrak{f}}$ & Fraction \\
\hline P $1 \mathrm{a}$ & 6.75 & F 6 & 2.2 & 401.3 & f 9 & 0.43 & 4-III \\
\hline P I b & 6.75 & F 6 & 2.2 & 401.3 & f 8 & 0.40 & $4-1$ \\
\hline$P_{2}$ & 6.53 & - & 10.0 & - & - & - & ? \\
\hline P $3 a$ & 6.45 & - & 16.5 & - & - & - & $?$ \\
\hline P $3 b$ & 6.45 & - & 21.0 & - & - & - & ? \\
\hline P $4 a$ & 6.27 & F 7 & 1.6 & 403.1 & (f 10 ) & 0.46 & $?$ \\
\hline P 4b & 6.27 & F $5 a$ & 3.0 & 402.5 & f 7 & 0.34 & $5-I I I$ \\
\hline P 4c & 6.27 & F 5 & 3.6 & 402.3 & f 6 & 0.29 & $5-I$ \\
\hline P $5 a$ & 5.98 & F 4 & 5.4 & 403.5 & f 5 & 0.19 & 6-III \\
\hline P $5 b$ & 5.98 & F $3 a$ & 6.8 & 403.4 & & & $6-1$ \\
\hline P $5 c$ & 5.98 & F 3a & 7.3 & 403.3 & f $3 / 4$ & 0.10 & ? \\
\hline P 6 & 5.94 & - & - & - & - & - & ? \\
\hline P 7 & 5.88 & - & - & - & - & - & $?$ \\
\hline P 8 & 5.82 & - & - & - & - & - & $?$ \\
\hline P 9a & 5.72 & F 2 & 16.0 & 404.6 & f 2 & 0.05 & $7-\mathrm{III}$ \\
\hline P 9b & 5.72 & - & 20.5 & 404.4 & - & - & 7 -I \\
\hline P 9c & 5.72 & - & 24.2 & - & - & - & ? \\
\hline P 10 & 5.58 & (F 3) & 9.0 & 405.6 & - & - & ? \\
\hline P $11 \mathrm{a}$ & 5.48 & F 8 & 1.2 & 405.9 & (f 9 ) & 0.43 & ? \\
\hline P $11 \mathrm{~b}$ & 5.48 & - & 3.1 & 405.2 & - & - & ? \\
\hline$P 11 \mathrm{c}$ & 5.48 & - & 4.1 & 405.7 & - & - & ? \\
\hline$P 11 \mathrm{~d}$ & 5.48 & (F 3) & 8.8 & 405.9 & - & - & $?$ \\
\hline P $11 \mathrm{e}$ & 5.48 & F $1 \mathrm{a}$ & 23.5 & 405.7 & f 1 & 0.02 & 8 -III \\
\hline$P 11 \mathrm{f}$ & 5.48 & F 1 & 27.8 & 405.7 & f 1 & 0.02 & $8-I$ \\
\hline$P_{12}$ & 5.28 & - & (2.4) & $(405.9)$ & - & - & ? \\
\hline P 13 & 5.12 & - & (4.4) & $(405.9)$ & - & - & ? \\
\hline P 14 & 5.04 & - & (20.5) & $(405.9)$ & - & - & ? \\
\hline
\end{tabular}

On separating the other oligocarboxyl porphyrins (hepta- (P 9), hexa- (P 5), penta- (P 4) and tetracarboxyl (P 1) porphyrins) in the partition system $\mathrm{TBP} / 1 \mathrm{~N} \mathrm{HCl}$, not more than 3 single fractions were obtained in any separation. This finding indicated that the anomalous substituents are apparently introduced into the porphyrin molecule before or during the enzymic condensation of porphobilinogen.

Other authors have pointed out $(13,14)$ that porphobilinogen occasionally occurs in different chemical constitutions. From this finding one may assume that the abnormality originates in one of the first steps of the biosynthesis of the haem, probably in the condensation of succinyl coenzym $A$ and glycine to $\alpha$-amino- $\beta$ ketoadipic acid and $\delta$-aminolevulinic acid. However further investigations are still necessary, to give any explanation of the occurrence of this abnormality in the porphyrin molecule. Unfortunately our Patient U. died before our experimental studies were concluded. Therefore the compounds in question could not be isolated in amounts sufficient for elucidation of the structure and determination of the anomalous substituents.

These finding also explain the occurrence of spots in the thin layer separations at low $R_{F}$ (Fig. 10), which were first considered to be a contamination by the predominant fractions of 8-I, III and 7-III. 


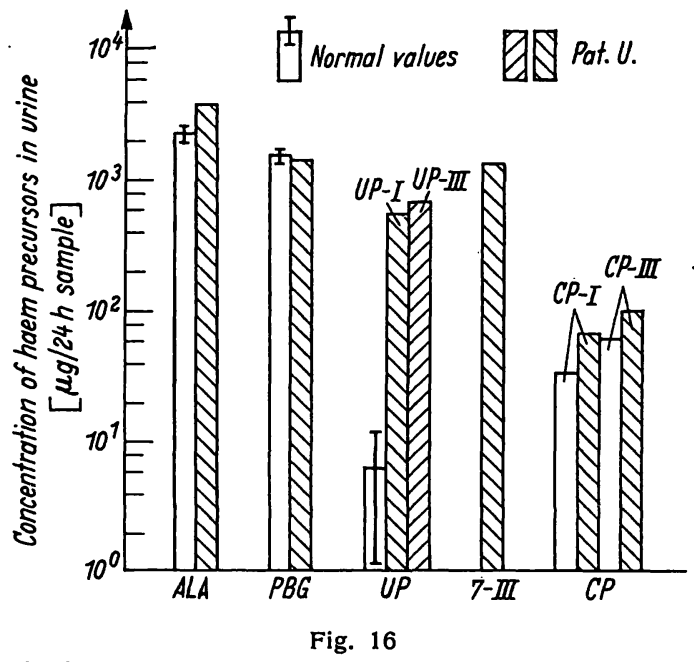

A compilation of the daily excretion rates of the most predominant haem precursors occurring in the urine of Patient U. (hatched columns). The normal ranges are given for comparison (open columns)

ALA $=\delta$-aminolevulinic acid $\quad 7$-III $=$ heptacarboxylporphyrin PBG = porphobilinogen $\begin{aligned}-I I I & =\text { heptacarboxylp } \\ \text { (series III) } & \\ C P & =\text { Coproporphyrin }\end{aligned}$

Quantitative data of some prominent compounds in the urine of Patient $U$. are compiled in Figure 16, together with the corresponding normal ranges. While $\delta$-aminolevulinic acid $(3.7 \mathrm{mg} / 24 \mathrm{~h})$, porphobilinogen $(1.4 \mathrm{mg} / 24 \mathrm{~h}$ ), coproporphyrin-I and III (64 and $96 \mu \mathrm{g} /$ $24 \mathrm{hr}$, resp.) occurred in the urine in concentrations equal or only slightly increased in comparison to the normal values, uroporphyrin-I and III (540 and $660 \mu \mathrm{g} /$ $24 \mathrm{~h})$ and the heptacarboxyl porphyrin 7-III $(1300 \mu \mathrm{g} /$ $24 \mathrm{~h}$ ) were excreted in amounts more than a hundred times that of the normal ranges.

Although huge amounts of uroporphyrin-I and III and 7-III were synthesized, the erythropoesis is significantly inhibited. Bearing in mind that:

1. the iron utilization is evidently lowered (Fig. 1),

2. the incorporation of iron by sternum and sacrum was decreased,

3. the iron level in plasma was increased $(152 \mu \mathrm{g} /$ $100 \mathrm{~m} /$,

we may assume that, besides the disordered synthesis, the iron transport by transferrin to the haemoglobin synthesizing erythroblasts may be also a limiting step of the biosynthesis of the haem in our case.

\section{References}

1. FalK, J. E. and A. Benson, Biochem. J. 55, 101 (1963). 2. Cornford, P. A. D. and A. Benson, J. Chromatog. 10, 141 (1963). - 3. ERIKSEN, L., Scand. J. Clin. Laborat. Invest. 10, 319 (1958). - 4. MundsChenk, H., J. Chromatog. 25, 380 (1966). 5. Kent, R. and W. Stich, Hoppe-Seyler's Z. physiol. Chem. 289, 6 (1951). - 6. MundsCHENK, H., J. Chromatog. 37, 431 (1968). - 7. Mundschenk, H., J. Chromatog. 38,106 (1968). 8. Mundschenk, H., J. Chromatog., 40, 396 (1969) - 9. Mund
SChenk, H., Z. Analÿt. Chem., in press. - 10. Mundschenk, H., Z. Analyt. Chem. 233, 25 (1968). - 11. Edmondson, P. R. and S. Schwartz, J. biol. Chemistry 205, 605 (1953). - 12. FalK, J. E., E. I. B. Dresel, A. Benson and B. C. KNIGHT, Biochem. J. 63, 87 (1956). - 13. SchwarTz, S., M. Keprios and R. Schmid, Proc. Soc. Exp. Biol. Med. 79, 463 (1952). - 14. Cooksov, J. H. and C. Rimington, Biochem. J. 57, 476 (1954). - 15. Falk, J. E., J. Chromatog. 5, 277 (1961).
Dr. H. Mundschenk 6500 Mainz Langenbeçsstr. 1 